This document is the Accepted Manuscript version of the following article: Kathleen Lewis, John Skinner, James Finch, Tina Kaho, Marguerite Newbold, and Keith Bardon, 'Scoring and ranking farmland conservation activities to evaluate environmental performance and encourage sustainable farming', Sustainable Development, Vol. 5 (2): 71-77, version of record online 4 December 1998.

The final, published version is available online at:

http://onlinelibrary.wiley.com/doi/10.1002/(SICI)1099-

1719(199708)5:2\%3C71::AID-SD61\%3E3.0.CO;2-F/pdf

(C) 1997 by John Wiley \& Sons, Ltd and ERP Environment. 


\title{
SCORING AND RANKING FARMLAND CONSERVATION ACTIVITIES TO EVALUATE ENVIRONMENTAL PERFORMANCE AND ENCOURAGE SUSTAINABLE FARMING
}

\author{
K A Lewis, J Tzilivakis, J A Skinner, J Finch, T M Kähö, M J Newbold and K S Bardon
}

\begin{abstract}
The University of Hertfordshire, in collaboration with two UK agricultural establishments ADAS and IACR-Rothamsted are developing a computerised decision support system for environmental management of arable agriculture. Part of this system is aimed towards encouraging sound farmland conservation to protect existing plants and animals, to encourage greater biodiversity and to help the farming community adopt more sustainable practices. The software aims to assess performance, help identify areas where improvements to existing habitats can be made and highlight the potential for new habitat creation. The assessment routines used determine a numerical eco-rating and textual description of performance by comparing actual practices with best practice.
\end{abstract}

\section{INTRODUCTION}

Wildlife conservation is a much discussed topic at all levels of expertise from scientists and policy makers to the layman. To many this can be a highly emotive subject and there is undoubtedly widespread concern regarding the decline of wildlife habitats and biodiversity (Bull et al, 1976, Fry, 1991) especially in areas of intensive farming such as lowland England.

There are many well debated reasons why this is occurring. Intensive farming and gradual changes in farming practices are partly responsible. The continual decrease in the size of the UK's dairy herd (FMA, 1993) means that many farmers no longer require hedges as stock-proof barriers consequently these have been removed to provide better machinery access. Hedges have also been removed to increase field size to help satisfy the demand for inexpensive, high quality produce. The desire for high yields has encouraged a greater dependency on pesticides which in turn has caused a wide variety of environmental problems including polluted watercourses and damage to non-target and beneficial species. The use of fertilisers to encourage high yields has caused problems with nutrient enrichment of waterbodies and contamination of drinking water supplies.

Another problem which is widespread on farmland where open fields with little or no boundaries are common, is habitat fragmentation. This physical isolation has significant impact on biodiversity. Wildlife 'corridors' linking habitats are seen as important by many authors (Jepson, 1994, Bennett, 1990). It is thought that many species are less likely to move and colonise new areas if these corridors are absent. Long distances between different habitats may also affect the food chain. The need for conservation and more sustainable farming practices has grown as the impacts of human activity have increased.

These problems have been widely recognised by Government and there have been many initiatives to protect declining species, encourage biodiversity and to designate certain areas as particularly important, needing special management and support. These areas include the 'Environmental Sensitive Areas (ESA's)', the Countryside Stewardship Scheme (CCS's), 'Sites of Special Scientific Interest (SSSI's)' and local nature reserves. Following the publication of 'Our Common Future' by the World Commission on Environment and Development in 1987, the concept of sustainable development has been discussed extensively. Sustainability demands that we must meet the needs of the present without compromising the ability of future generations to meet their own needs. Of the sites mentioned the ESA has a clear objective of encouraging sustainable agriculture and in particular 
minimising habitat and loss of species. However, whilst other sites such as CSS's and SSSI's are unquestionably valuable, they do not tackle the more widespread problem of unsustainable agriculture such as the loss of biodiversity and farmland habitats, ground and surface water contamination. Clearly the decisions and actions taken by individuals, such as farmers, are crucial to conservation at the local scale.

Various organisations, in particular the Farming and Wildlife Advisory Group (FWAG), are working to promote farm based conservation activities without jeopardising farm profitability. These organisations seek to boost farmers awareness using a combination of farm visits, literature and videos to identify farm potential for encouraging and enhancing wildlife. LEAF (Linking Environment And Farming) has been advocating the benefits of self-appraisal techniques. In 1994 they launched a check-list audit designed as a series of forms to be completed by the farmer on an annual basis (LEAF, 1994). This audit covers a range of farm activities including wildlife and habitat conservation to encourage sound environmental practices on the farm. Whilst a positive first step, the self-administered appraisal in isolation is unlikely to be completely effective. The LEAF audit does not provide the farmer with any feed-back nor does it indicate where improvements can be made (Newbold et al, 1996). Earlier this year the Advisory Committee on Business and the Environment in its sixth progress report to the President of the Board of Trade (ACBE, 1996) recommended the use of self-appraisal techniques but they also recognised that farmers may need more help to understand and build on the results of the audit properly. What appears to be required is a comprehensive decision support system to help farmers assess their practices, evaluate the value of their habitats and to identify ways of making improvements.

The University of Hertfordshire, in collaboration with ADAS and IACR-Rothamsted, is currently developing such a decision support system. As is the case with the more formal environmental management systems such as BS7750 and ISO14001 the computer based system aims to enable quality environmental management. More specifically it is:

- generic in the context of arable agriculture;

- encompasses the concept of sustainable development;

- pro-active based upon the principles of anticipation and prevention; and

- systematic based upon detailed documented procedures.

Part of this system is devoted to wildlife conservation and this paper details the work to date.

\section{THE METHODOLOGY}

One of the most important issues in developing such a system is the level of attention that is required with respect to both the man-machine interface and the data content. Both aspects are equally important. If the visual presentation and ease-of-use are inadequate, the system will not be used. The same will occur if the data content is insufficient, incorrect or out of date. Environmental performance evaluation needs objective criteria against which actual performance can be judged. Such criteria can be set, for example, empirically as specific targets of environmental policy or can be comparative exercises such as comparing actual performance to a 'model' or 'ideal' farm. Comparison with a model farm is rarely practical. No two farms are identical. Each will have different soil types, carry out different activities and grow different crops or keep different livestock. The geology and climate will probably vary and each farm will have different features such as woodland, ponds or rivers. One approach to solving this problem is to sub-divide the model farm up into 'activities' (use of fertilisers, pesticides, livestock management, conservation etc.) and assess each activity separately against rules describing 'best practice'. Best practice will vary to reflect differing situations and a unique rule-base can be selected to suit the farm being assessed.

The comparison exercise itself presents another set of difficulties. Much of the data associated with conservation (and many other farm activities) is observational and qualitative rather than quantitative, for example 'When are field margins mowed?' or "Is the pond heavily shaded by trees?". 
Consequently, whilst it is relatively easy to produce a textual analysis of the data, for example 'Margins should be mowed in the autumn' or 'Trees should be thinned to let sunlight through to watercourses', it is less easy to derive a numerical measure. However, such a numerical indicator on a defined scale is, ideally, required.

There are various methods of translating visual and qualitative information into numerical representations. One technique commonly used is scoring and ranking the responses to a specifically designed questionnaire often in the form of a checklist. This method provides a scale for measurement and judgement and can be used to convert quite complex information into a simpler format, by, for example, awarding individual scores to individual questions centred around a main theme, then aggregating the scores to produce an overall score or index. The checklist approach has been used for many applications and, in particular, has found several applications in the United States. The US Federal Highway Administration has used it to evaluate wetlands before and after a major development. The US Fish and Wildlife Service and the US Army Corps of Engineers have both developed similar systems to assess wildlife habitats (Erickson, 1994).

These techniques depend upon the identification of environmental components and processes which help formulate a 'snapshot' of the environmental status. For example, the 'ideal' pond, should have, amongst other things, a variety of depths, at least one gently sloping bank, be partially shaded, should be unpolluted and physically linked to other habitats. The questionnaire needs to be designed to gain information on all these aspects. However, considerable care is required to keep the list of questions as short as possible to avoid loosing the interest of the participant i.e. the farmer. It is also important to avoid asking leading questions such as 'Is you pond healthy?' otherwise the quality of the information obtained may be dubious. Scoring and ranking methods need careful thought in application. Although seemingly simple at a superficial level, to be effective they must be periodically assessed, unbiased, correctly weighted and enable evaluation to an acceptable depth.

\section{SCORING AND RANKING}

Scores are artificial numbers attributed to particular events or actions. More specifically a score can be seen as a numerical representation of the relative importance of an environmental (or other) effect. Wehrmeyer (1995) demonstrates this process with the hypothetical example, shown in Table 1, using two alternative methods of scoring water pollution. In system 1 the total points awarded has no theoretical maximum. If all variables are included, under system 2 the maximum is 20 . Both systems are correct and both have their own advantages and disadvantages. System 1, having an undefined maximum, may introduce problems in interpreting the data. The higher the score the worse the performance but at what point is the performance unacceptable? System 2, having a theoretical maximum may not truely reflect a very poor performance, if, say, the COD was frequently well above the goal of $30 \mathrm{mg} / \mathrm{l}$.

Whilst some workers in this area have criticised scoring and ranking as being overly simplistic (Thompson, 1988) such methods can provide an essential starting point and sometimes the only practical means, for systems whose underlying complexities are not fully understood or agreed (Tucker et al, 1996).

The disadvantages of this technique are mainly associated with the arbitrary nature of assigning scores. However, if this is kept in mind, scoring methods, if uniformly applied, can be designed to successfully compare a variety of different environmental performance areas.

Ranking may be seen as the natural consequence of scoring. In terms of the environment, risks and hazards are often ranked in order to represent the probability of events occurring or the significance of the impacts in relation to each other. This technique has had many applications within environmental management including the assessment of contaminated sites (Myres et al, 1994) and assessing the impact of pesticides (Reus \& Pak, 1993, Hayo \& van der Werf, 1996). 


\begin{tabular}{|c|c|c|c|c|}
\hline \multirow[t]{2}{*}{ Variable } & \multirow[t]{2}{*}{ Goal } & \multirow[t]{2}{*}{ Scoring System 1} & \multicolumn{2}{|c|}{ Scoring System 2} \\
\hline & & & Variable range & score \\
\hline $\mathrm{pH}$ & 5.0 to 8.0 & & $\mathrm{pH}$ within limit & 1 \\
\hline & & & $6.0-8.0$ & 2 \\
\hline & & & $6.5-7.8$ & 3 \\
\hline & & & $6.8-7.5$ & 4 \\
\hline & & & $7.0-7.2$ & 5 \\
\hline Biological & $<50 \mathrm{mg} / \mathrm{l}$ & For each of the variables & meets limit & 0 \\
\hline Oxygen & & one point is assigned for & $<40$ & 1 \\
\hline Demand & & every 20 days the target & $<35$ & 2 \\
\hline$(\mathrm{COD})$ & & is met. & $<30$ & 3 \\
\hline & & & $<25$ & 4 \\
\hline & & & $<20$ & 5 \\
\hline Chemical & $<30 \mathrm{mg} / \mathrm{l}$ & & $95 \%$ of time below limit & 1 \\
\hline Oxygen & & & $95 \%$ of time below 25 & 2 \\
\hline Demand & & & $95 \%$ of time below 20 & 3 \\
\hline (COD) & & & $\begin{array}{l}95 \% \text { of time below } 15 \\
99 \% \text { of time below } 15\end{array}$ & $\begin{array}{l}4 \\
5\end{array}$ \\
\hline Suspended & $<200 \mathrm{mg} / \mathrm{l}$ & & $>10$ failures last month & 0 \\
\hline Solids & & & 10 failures last month & 1 \\
\hline & & & 8 failures last month & 2 \\
\hline & & & 6 failures last month & 3 \\
\hline & & & $\begin{array}{l}4 \text { failures last month } \\
<2 \text { failures last month }\end{array}$ & $\begin{array}{l}4 \\
5\end{array}$ \\
\hline
\end{tabular}

Table 1: Example of simple scoring systems (After Wehrmeyer, 1995)

\section{THE ECO-RATING SYSTEM}

Generally, such scoring and ranking systems introduce maximum and minimum values on a theoretical scale. Sometimes, as in the Wehrmeyer example, the scale may be open ended. In these cases there may be advantages in constraining the maximum and minimum values especially if scores are to be aggregated on a wider scale in order to prevent bias or rogue values swamping other data. Often scales have a zero minimum value indicating the worst case scenario and a positive maximum. Within the computer system developed at the University of Hertfordshire a slightly different approach has been used. The eco-rating system spans a positive-negative scale as shown in Figure 1. The positive values represents an environmental gain, the negative values represent environmental damage. The zero point indicates a neutral activity and maybe thought of as the threshold of sustainability. With respect to conservation issues the establishment of a pond or planting of a new woodland of native species would represent a true environmental gain and therefore the eco-rating would be positive. Filling in a pond or removing hedgerows would represent a loss to the environment and a negative rating would be assigned.

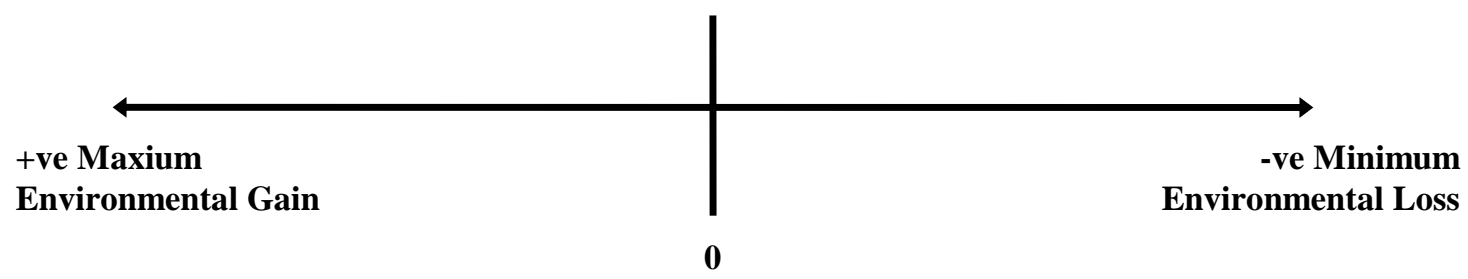

Threshold of Sustainability 


\section{FARMLAND CONSERVATION}

Conservation carried out on a farm will cover a variety of activities. Some are specific to individual habitats such as ponds, rivers or woodlands. Others are more general relating to, for example, the protection of wildlife from farm chemicals and wastes or providing exit routes from cattle grids. The range of habitats present will vary from farm to farm. The computer system being described here subdivides conservation activities into a number of areas which can be linked in or omitted as appropriate. The areas included are: general farm management, hedges, field margins, woodlands and water bodies. Water bodies are further sub-divided into (i) standing freshwater systems such as ponds and lakes and (ii) running freshwater systems such as watercourses, ditches and wetlands.

Within each area a set of checklist, multiple choice type questions have been developed to describe best to worst practice. Each possible response has an assigned score. The users responses are summed to determine the eco-rating. The scale range and the eco-rating of each area is normalised to span a +250 to -250 scale. The scale is divided to give four broad performance bands: good, above acceptable, below acceptable and poor. Acceptable is equated with the threshold of sustainability, that is the zero point. The performance band descriptors are rather subjective, however they do help the user to more fully comprehend their own performance. An associated key supplies the user with further information on band ranges.

\section{General Farm Management}

Several conservation issues are covered within the area on general farm management. Activities and management practices to protect wildlife from poisoning or accident are especially highlighted, for example, the provision of escape routes from cattle grids and water troughs and complying with label precautions on pesticides such as wood preservatives and rodenticides. Special attention is also given to activities which help encourage wildlife breeding such as the provision of nesting boxes for birds and bats and, for example, avoiding the disturbance of dens and lairs so as not to cause adults to abandon their young.

\section{Hedge Management}

Retention and management of hedgerows on the farm is one of the most important aspects of farmland conservation but one that is often neglected. The eco-rating routines concerned with conservation of hedges assess both the quality and the length of the hedgerow. With respect to length, equation (1) is used to determine a score $\left(\mathrm{H}_{\mathrm{R}}\right)$ associated with the length of the hedgerow at the end of the assessment year as compared to its length at the start of the year. A negative score is obtained if hedges have been removed and a positive score if hedges have been planted.

$$
H_{R}=\operatorname{Int}\left(\left(L_{p}-L_{R}\right) / L\right) \times 9
$$

Where $L_{p}$ is the length planted and $L_{R}$ is the length removed. $L$ is the length at the start of the year. The maximum positive score is constrained to +9 and the minimum possible, if all hedges were removed, is -9. For unlaid hedges, the baseline rating $\left(\mathrm{H}_{\mathrm{R}}\right)$ is enhanced depending upon the quality of the hedge such as its height and width, the percentage which is gap and whether or not the hedgerow is comprised of native and/or non-native species. An example of the scores assigned is given in Table 2 .

\begin{tabular}{l|l|l|l|} 
Height & Score & Width & Score \\
\hline
\end{tabular}




\begin{tabular}{|c|c|c|c|}
\hline $0-1 \mathrm{~m}$ & 0 & $0-1 \mathrm{~m}$ & 0 \\
\hline $1-2 \mathrm{~m}$ & 1 & $1-2 \mathrm{~m}$ & 1 \\
\hline $2-3 \mathrm{~m}$ & 2 & $2-3 \mathrm{~m}$ & 2 \\
\hline $4 \mathrm{~m}+$ & 3 & $3 \mathrm{~m}+$ & 3 \\
\hline
\end{tabular}

Table 2: Typical scores assigned for hedge dimensions.

Management activities, for example, when and by how much hedges are trimmed are also scored, as are the numbers of standard trees and the provision and protection of buffer zones.

\section{Field Margin Management}

Field margins are considered very important on farms to wildlife (FWAG, undated). They act as links or corridors allowing birds, insects and small mammals to move from one area to another. These areas also support many beneficial insects which are natural predators to many crop pests. For conservation purposes and to encourage insects it is important to create a stable plant base. The ecorating system assesses the current value of these areas on the farm by looking specifically at when margins are mowed, how wide they are, their protection from pesticides and from inorganic and organic fertilisers.

\section{Water bodies}

Field ponds were once a vital part of many farms, but the intensification of farming has meant that many of these important habitats have been neglected or filled in. A Survey carried out in 1988 suggested that Britain has lost over 180,000 ponds since 1945 (Swan \& Oldham, 1989). Wetlands, although biologically diverse have often been seen as waste land awaiting reclamation. The assessment routine for water bodies is sub-divided into two parts (i) enclosed water habitats such as ponds and lakes and (ii) flowing water such as ditches, watercourses and wetlands. In order for the value of these sites to be maximised care needs to be given to ensuring the quality of the water, the provision and maintenance of wildlife islands and other habitats close by. As well as these issues, the checklist audit also considers whether or not significant sunlight is reaching the waters surface and the risk of pollution from, for example, tree leaf litter or the lack of buffer zones. Ditch management is tackled by looking at when and how they are cleared, dredged and techniques used for weed control. An example of the checklist audit, the assigned scores and typical accompanying text is given in table 3.

\begin{tabular}{|c|c|c|}
\hline Question & Score & Typical Text \\
\hline $\begin{array}{l}\text { When do you dredge your } \\
\text { ditches? } \\
\square \text { In spring } \\
\square \text { In summer } \\
\square \text { In autumn } \\
\square \text { In winter }\end{array}$ & $\begin{array}{r}-3 \\
-6 \\
+6 \\
+3\end{array}$ & $\begin{array}{l}\text { Ditches should be dredged during the autumn to } \\
\text { avoid disturbing wildlife until after the } \\
\text { breeding season and when young have matured. } \\
\text { If ditches are not dredged from time to time } \\
\text { they may silt up and loose their habitat value. }\end{array}$ \\
\hline $\begin{array}{l}\text { What proportion of your ditches } \\
\text { do you clear in a year? } \\
\square 0-25 \% \\
\square 26-50 \% \\
\square 51-75 \% \\
\square 76-100 \%\end{array}$ & $\begin{array}{l}+6 \\
+3 \\
-3 \\
-6 \\
\end{array}$ & $\begin{array}{l}\text { Ditches should be cleared in short lengths in } \\
\text { rotation every } 5 \text { years or so to give plants and } \\
\text { animals the chance to recolonise treated areas. } \\
\text { It will also be beneficial to only clear one bank } \\
\text { at a time. }\end{array}$ \\
\hline
\end{tabular}

Table 3: Part of a Checklist Audit Questionnaire 


\section{Woodland Management}

The woodland audit is tackled in a similar manner to hedgerows. The baseline score $\left(\mathrm{W}_{\mathrm{R}}\right)$ is derived from a simple equation (2) which compares the area of woodland on the farm at the beginning of the year with that at the end of the year.

$$
\mathrm{W}_{\mathrm{R}}=\operatorname{Int}\left(\left(\mathrm{W}_{\mathrm{p}}-\mathrm{W}_{\mathrm{R}}\right) / \mathrm{W}\right) \times 9
$$

Where $\mathrm{W}_{\mathrm{p}}$ is the area planted and $\mathrm{W}_{\mathrm{R}}$ is the area removed. $\mathrm{W}$ is the area at the start of the year. The maximum positive score is constrained to +9 and the minimum possible, if all woodland has been removed, is -9 .

This baseline eco-rating for woodland $\left(\mathrm{W}_{\mathrm{R}}\right)$ is then enhanced by assessing woodland management, how many trees there are per hectare, the presence of other features such as fallen deadwood, shrubs and ground vegetation and links or corridors to other habitats (ditches. hedges, ponds etc.) on the farm.

\section{THE ASSESSMENT PROCESS}

The purpose of establishing an environmental management system or carrying out an impact assessment is not to further scientific knowledge but to enable enhanced environmental performance through an improved decision making process. This will ensure that the environmental consequences, good and bad, of human activities are understood and taken into account.

The computer system described here carries out the assessment process via a series of linked tasks as shown in Figure 2. Tasks 1 and 8 outside the dotted box are related to the farmer's conservation practices. Task 1 is associated with the gathering and collation of observational and qualitative data relating to existing habitats and farm practices. For example, determining how much of the hedgerow is gap or how much hedge has been removed in the past year. Task 8 relates to the amendment of practices and the carrying out of new projects. The process is continuous; task 8 leading directly, with time, back to task 1 to initiate a fresh review and assessment.

Inside the dotted box are tasks 2 to 7 . These are associated with the software itself. The first task is to describe the farm profile. Information on farm size, geology, local climate and existing habitats is declared. Task 2 refers to the checklist audit questionnaire. The user is asked a series of questions designed to obtain information on the current environmental status of farm habitats. Tasks 4 and 5 are embedded procedures within the computer system which compare the information gathered with rules of best practice. Tasks 6 and 7 refer to other procedures to identify priority areas for improvements and to make recommendations. 


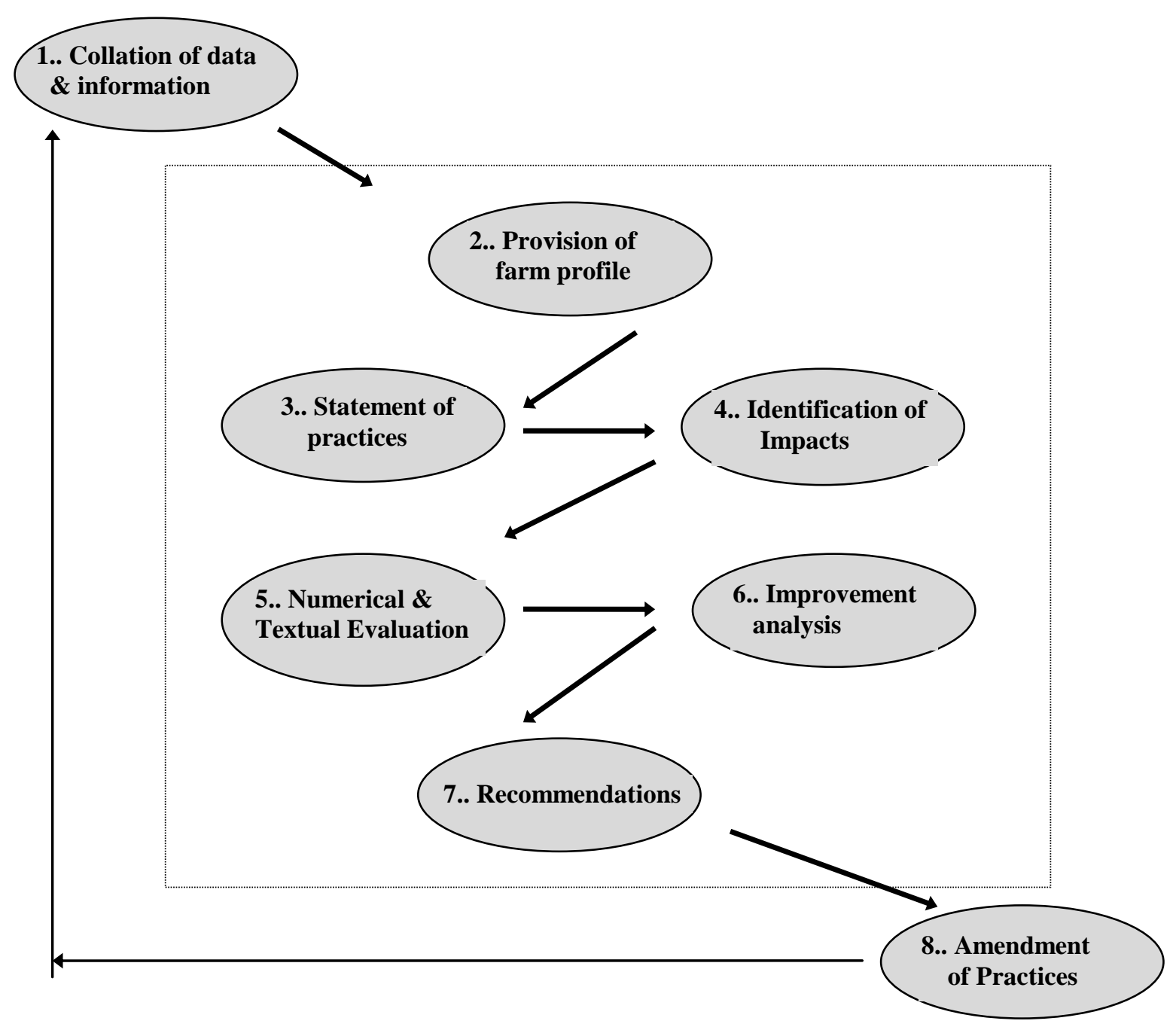

Figure 2: The Environmental Assessment Process

\section{CONCLUSION}

The conservation of existing wildlife and habitats should be given a high priority within the overall farm management plan if the decline of habitats in the UK is to be stopped and if the farming community is to help strive for sustainability. The conservation eco-rating system and supporting software described here is part of a more general system designed to be used by consultants and farmers to review environmental performance and to monitor progress towards improvements within arable agriculture. The assessment routines provide the user with a simple numerical indicator of performance which, coupled with the text descriptions, allow farmers to identify areas where improvements can be made. The system helps to identify priority areas for action, encourages continuous improvements and can be customised to suit individual farms.

\section{ACKNOWLEDGEMENT}

The research project described here is funded by the UK's Ministry of Agriculture, Fisheries and Food and has been carried out in collaboration with ADAS and IACR-Rothamsted. The help and advice from the Ministry and from other organisations is gratefully acknowledged, especially that of 
FWAG, whose advice and support has been most welcome. The views expressed in this paper are those of the authors and not necessarily those of the Ministry.

\section{REFERENCES}

- Advisory Committee on Business and the Environment (ACBE) (1996) 6th Progress Report.

- Bennett, A.F. (1990) Habitat Corridors - Their Role in Wildlife Management and Conservation. Melbourne: Department of Conservation and Environment.

- Bull, A.L., Mead, C.J., and Williamson, K. (1976) Bird Life on a Norfolk Farm in Relation to Agricultural Changes. Bird Study 23, 163.

- Erickson, P.A. (1994) A Practical Guide to Environmental Assessment. Academic Press

- Fry, G.L.A. (1991) Conservation in Agricultural Systems. The Scientific Management of Temperate Communities for Conservation. PP 415-443. I F Spellerberg, F B Goldsmith and M G Morris (Eds). Blackwell, Oxford.

- Fertiliser Manufacturers Association (FMA). (1993) Fertiliser Review.

- FWAG (Undated) Farming and Field Margins Information leaflet.

- Hayo, M.G. van der Werf, (1996) Assessing the Impact of Pesticides on the Environment. In press. INRA France.

- Jepson, P.C. (1994) Field Margins as Habitats, Refuges and Barriers of Variable Permeability to Carabidae. BCPV Monograph N. 58: Field Margins: Integrating agriculture and Conservation. pp 67 - 76

- The LEAF Environmental Audit (1994) Stoneleigh, Warwickshire

- Myres, K., Vogt, T. and Wales, J. (1994) Hazard Ranking Criteria for Contaminated Sites. Land Contamination and Reclamation. 2, 1 pp13-18.

- Newbold, M.J.,Lewis, K.A.,Tzilivakis, J., Finch, J., Kaho, T.M. and Bardon, K.S. (1996) The Options for Informal Environmental Management: The Agricultural Industry Highlighted. Eco-Management and Auditing Journal. In press

- Reus, J.A.W.A. and Pak, G.A. (1993) An Environmental Yardstick for Pesticides. Med. Fac. Landbouww. Univ. Gent, 58/2a: pp 249-255

- Swan, M.J.S. and Oldham, R.S. (1989) Amphibian Communities. Nature Conservancy Council Commissioned Research Report. No. 1020.

- Thompson, M.A. (1990) Determining Impact Significance in EIA: A Review of 24 Methodologies. Journal of Environmental Management. 30

- Tucker, P., Lewis, K.A., Skinner, J.A. (1996) Environmental Management in Agriculture: An Expert System Approach. Eco-Management and Auditing 3,3 pp 9-14

- Wehrmeyer, W. (1995) Measuring Environmental Business Performance. A Comprehensive Guide. Business and the Environment - Practitioner Series. Ruth Hillary (Ed) Stanley Thornes.

The authors may be contacted at:

Division of Environmental Sciences,

University of Hertfordshire,

Hatfield Campus, College Lane, Hatfield,

Hertfordshire AL10 9AB, UK.

Tel: 01707284582

Fax: 01707284514

E-mail: K.A.Lewis@herts.ac.uk 